\title{
A novel microstrip triple wideband bandstop filter design by using adjacent direct coupled dual-mode resonators
}

\section{Bitişik direk kuplajlı çift-modlu rezonato̊rler kullanılarak yeni bir mikroşerit üç geniş bantlı bant tutan filtre tasarımı}

\author{
Elif Güntürkün Şahin ${ }^{1 * *}$ \\ ${ }^{I}$ Niğde Ömer Halisdemir Üniversitesi, Elektrik Elektronik Mühendisliği Bölümü, 51240, Niğde Türkiye
}

\begin{abstract}
In this article, a novel triple wideband bandstop filter design is proposed with two adjacent microstrip square loop resonators (MSLR) having different edge lengths. Degenerate modes of the square loop resonators are induced by using direct coupling mechanism. Perturbation and loading elements are located on resonators and used to control reflection zeros between the second and third bands. Even odd mode analysis of a single direct coupled dualmode resonator is also extracted to elucidate the filter topology. The proposed resonator structure is designed by using a full-wave EM simulator and three different filter responses are obtained from the designed resonator structure. One of the filters is fabricated and, it is observed that measured results are compatible with simulated results
\end{abstract}

Keywords: Microstrip filter, Wideband, Dual-Mode resonator, Degenerate mode

\section{Introduction}

According to the recent developments of communication systems, multiple band filters are largely needed because of the density in the frequency band. Microwave filters have an important role to avoid these systems from unwanted signals and interferences, ext. Especially, these structures have compact size, low cost, low mass, high performance and also supply the essential requirements to use the frequency spectrum effectively.

To date, various types of microstrip filters have been investigated to introduce desired band characteristic in wideband applications. Although, there are many examples of bandpass filter (BPF) structures in the literature, multiple wideband bandstop filters (BSF) are quite limited. Dualmode microstrip resonators (DMR) such as circular ring, triangular patch or square loop resonators have been used to realize microstrip BSF since Wolff exhibit the degenerate modes of a circular DMR [1]. Despite these resonators are generally used in BPF applications, BSF designs which use degenerate modes of DMR have been preferred by the authors commonly. In [2], an example of a direct coupled circular ring resonator is given. Here, this resonator is excited by using asymmetrically coupled feeding lines. The strip width of the resonator has been changed in certain parts
Özet

$\mathrm{Bu}$ çalışmada iki adet farklı kenar uzunluğuna sahip birbirlerine bitişik olan mikroşerit kare halka rezonatör kullanılarak yeni bir üç geniş bantlı bant tutan filtre tasarımı yapılmıştır. Kare halka rezonatörler direk kuplaj yöntemi ile beslenerek dejenere modlarının uyarılması sağlanmıştır. Tasarlanan rezonatörler üzerinde perturbasyon ve yükleme elemanları var olup, dejenere modların arasındaki kuplaj değișimi ile filtrenin ikinci ve üçüncü bandları arasındaki yansıma sıfırları kontrol edilebilmiștir. Önerilen filtre topolojisini desteklemek için direk kuplajlı tek bir kare halka rezonatörün tek-çift mod analizi yapılmıştır. Geliştirilen rezonatör yapısı bir tam dalga EM benzetim programı kullanılarak tasarlanmış ve bu yapıdan üç farklı filtre cevabı elde edilmiştir. Filtrelerden bir tanesi gerçekleştirilmiş olup, sonuçlar uyum içerisindedir

Anahtar kelimeler: Mikroşerit filtre, Geniş band, Çiftmod rezonatör, Dejenere mod

of the loop due to the symmetry axis, to control the degenerate modes which transform into transmission zeros for the bandstop case. A closed rectangular loop resonator loaded with two open half stubs is given in [3]. An adjustable wideband bandstop filter is obtained by using a direct coupled loop resonator. Here, in despite of wide stopband is proposed, filter performance is low because of the filter degree and loop levels of passband. Direct coupled square ring resonators are often preferred in wideband filter design. In [4], perturbation element and open-ended stubs are used together to excite the degenerate modes increased by multiplying the number of resonators. This work suffers from the size of filter and performance of frequency response. Another direct coupled DMR design that has perturbation and L-shaped open loop resonator elements is given in [5] to realize UWB BPF response. Here, authors use the degenerate modes as transmission zeros and natural poles of the filters act as reflection poles. So, wide passband characteristic can be obtained. Besides them, in [6], an asymmetrically direct coupled DMR is excited to control the degenerate modes with loading elements. In this paper, a novel compact triple band BSF design is proposed by using two direct coupled adjacent square loop DMRs having different edge sizes. Loading elements acting as a conductive

\footnotetext{
* Sorumlu yazar / Corresponding author, e-posta / e-mail: elifsahin@ ohu.edu.tr (E. Güntürkün Şahin) Geliș / Recieved: 18.08.2021 Kabul / Accepted: 27.09.2021 Yayımlanma / Published: 14.01.2022 doi: 10.28948/ngmuh.983947
} 
patch elements and perturbation elements are used to control the degenerate modes and natural zeros of the filter, thus, reflection zeros (RZs) between the bands and in-band return loss (IL) levels in the stopband can be arranged. Three types of filtering responses (Filter-A, Filter-B and Filter-C) can be obtained by using only one filter structures. To clarify the proposed topology, even odd mode analyses of adjacent resonators are given under week coupling. One of the filters (Filter-A) is fabricated and measured by using a vector network analyzer. Measured RLs for each band are $-0.17 \mathrm{~dB}$, $0.38 \mathrm{~dB}$ and $2.46 \mathrm{~dB}$ respectively. These results are in good agreement with simulated ones

\section{Material and methods}

\subsection{Resonator analysis}

The proposed microstrip DMR with loading elements is illustrated in Figure 1(a). As can be seen from the figure, input and output ports of this resonator are coupled with lumped element capacitors to analyze the proposed resonator. As even odd mode equivalent half circuits constructed by locating electric and magnetic walls to the symmetrical axis of the loaded microstrip DMR are depicted in Figure 1(b) and (c), respectively. In equivalent circuit model, the effect of the loading elements is represented with a shunt capacitor which has $j B$ reactance that can be calculated as,

$$
\begin{gathered}
B \approx \frac{1}{Z_{02}}\left(\theta_{2}\right) \\
\theta_{2}=\frac{2 \pi}{\lambda_{g}} l
\end{gathered}
$$

where $Z_{02}, \theta_{2}$ and $\lambda_{g}$ are the characteristic impedance, electrical length and guided wavelength of the loading elements of dual-mode resonator, respectively. Also, $l$ is the length of the loading elements. In addition, scattering parameters can be calculated by using even odd mode input impedance formulas which are given below,

$$
\begin{aligned}
& S_{11}=\frac{Z_{\text {even }} Z_{\text {odd }}-Z_{o}{ }^{2}}{\left(\frac{Z_{\text {even }}+Z_{\text {odd }}}{2}+Z_{o}\right)^{2}-\left(\frac{Z_{\text {even }}-Z_{\text {odd }}}{2}\right)^{2}} \\
& S_{21}=\frac{\left(Z_{\text {even }}-Z_{\text {odd }}\right) Z_{o}}{\left(\frac{Z_{\text {even }}+Z_{\text {odd }}}{2}+Z_{o}\right)^{2}-\left(\frac{Z_{\text {even }}-Z_{\text {odd }}}{2}\right)^{2}}
\end{aligned}
$$

Here, $Z_{\text {even }}$ and $Z_{\text {odd }}$ are even-odd mode impedance equations, respectively. Also, $Z_{o}$ is chosen as $50 \Omega$ which is the impedance value of input and output port terminals. As can be seen from Figure 1(b), even-mode input impedance ( $Z_{\text {even }}$ ) for the DMR with loading elements may be expressed as,

$$
Z_{\text {even }}=\frac{1}{j \omega C_{g}}+\frac{1}{Y r_{\text {even }}}
$$

where $Y r_{\text {even }}$ is

$$
Y r_{\text {even }}=j Y_{o 1}\left[\frac{\left(\frac{B}{Y_{o 1}}+\tan \theta_{3}\right)+\tan \theta_{1}}{1-\tan \theta_{1}\left(\frac{B}{Y_{o 1}}+\tan \theta_{3}\right)}+\tan \theta_{4}\right]
$$

Additionally, odd-mode impedance $\left(Z_{\text {odd }}\right)$ can also be derived according to Figure 1(c),

$$
Z_{\text {odd }}=\frac{1}{j \omega C_{g}}+\frac{1}{Y r_{o d d}}
$$

where $Y r_{o d d}$ is

$$
Y r_{o d d}=j Y_{o 1}\left[\frac{\left(\frac{B}{Y_{o 1}}-\cot \theta_{3}\right)+\tan \theta_{1}}{1-\tan \theta_{1}\left(\frac{B}{Y_{o 1}}-\cot \theta_{3}\right)}+\tan \theta_{4}\right]
$$

Here, $Y_{o 1}$ and $Y_{o 2}$ are the characteristic admittance, $\theta_{1}$, $\theta_{2}, \theta_{3}$ and $\theta_{4}$ are the corresponding electrical length of the resonator and loading elements, respectively. Also, $C_{g}$ is the gap capacitance between the feed line and DMR. Here, $Y r_{\text {even }}$ and $Y r_{\text {odd }}$ are the admittance equations without the addition of $C_{g}$ capacitance for even odd mode case, respectively. As can be seen from the Equations (6) and (8), characteristic impedances and location of the loading elements have effects on both even and odd modes of the circuit. As is well known, even and odd mode resonance conditions can be obtained by equating $Z_{\text {even }}$ and $Z_{\text {odd }}$ to zero [7].

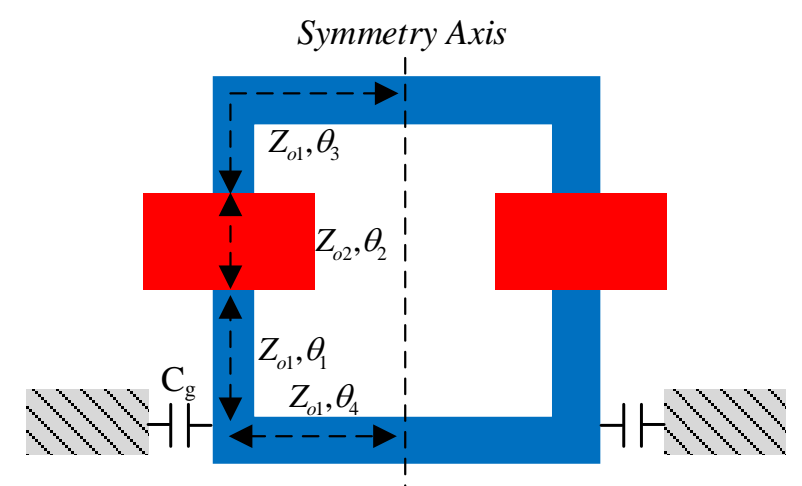

(a)

Figure1 (a). Proposed square loop DMR with loading elements 


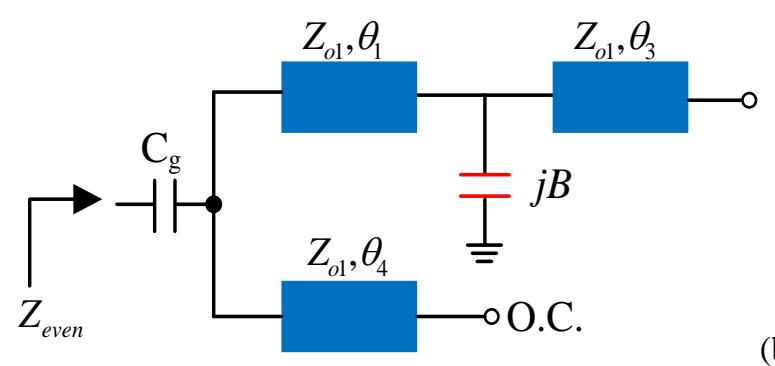

Figure1 (b). Even mode equivalent circuit model

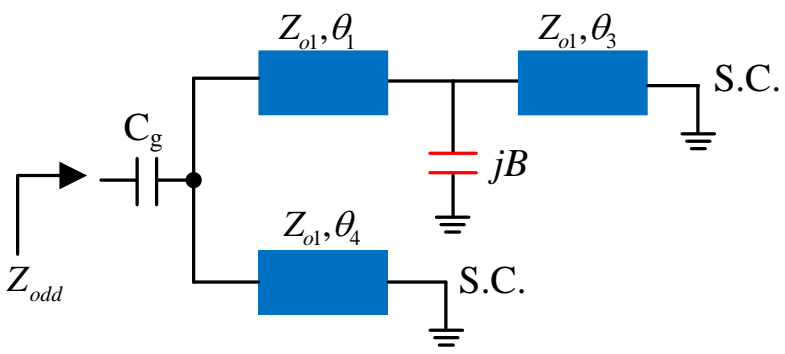

(c)

Figure1 (c). Odd mode equivalent circuit model

\subsection{Wideband bandstop filter design}

The proposed microstrip triple band BSF is shown in Figure 2. As can be seen from the figure, two square loop microstrip resonator with different side lengths are positioned adjacent to each other. Similarly, input and output ports $(\mathrm{I} / \mathrm{O})$ are directly connected to the resonator with the smaller side width. In addition, two identical loading elements are located on horizontal axis for each resonator to obtain desired band response. As is well known, degenerate modes of these adjacent DMRs can be excited by means of direct coupled I/O ports and perturbation elements, similar to the reference in [8]. So, the control of reflection zeros between the stop bands is related to the coupling of the degenerate modes.

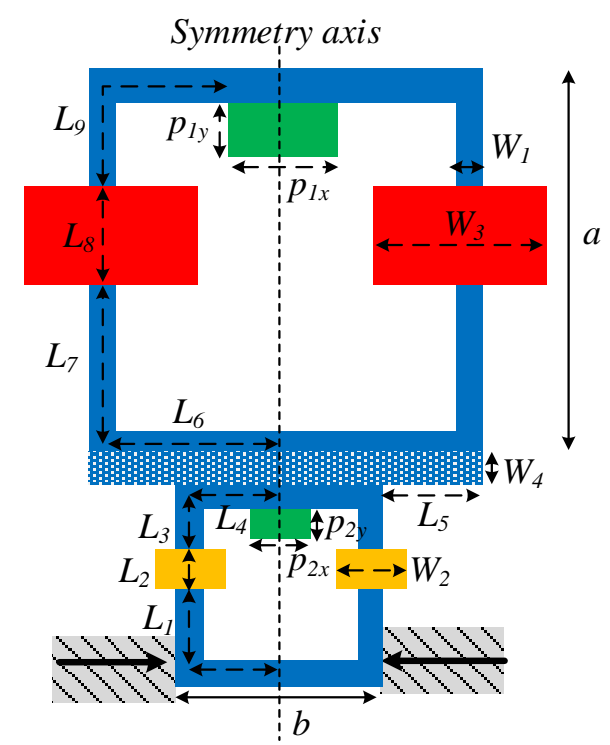

Figure 2. Layouts of the proposed structure
Three different BSF responses named as Filter-A, Filter$\mathrm{B}$ and Filter-C which are obtained by using triple band microstrip DMR design are shown in Figure 3. These filters can be realized by the control of RZs between the second and third band. The variation of loading and perturbation elements allows us to control the RZs by means of the coupling between the bands. As can be seen from the figure, for Filter-A, two RZs (fA $A_{R Z 11}$ and $f_{\text {RZ\#2 }}$ ) occur in real axis at 10.9 and $11.95 \mathrm{GHz}$, respectively. Also, for Filter-B, the RZs are shifted through real to imaginary frequency because of the coupling between the modes with respect to the reference in [8].

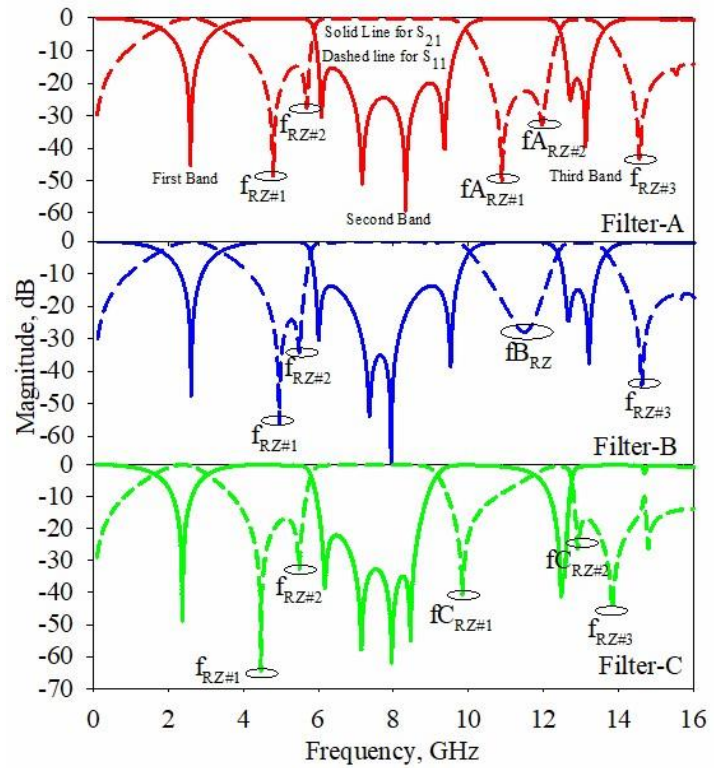

Figure 3. Simulated S-parameters for Filter-A, Filter-B and Filter-C

For Filter-C, two RZs ( $\mathrm{fC}_{\mathrm{RZ \# 1}}$ and $\mathrm{fC}_{\mathrm{RZ} 22}$ ) at 9.84 and 12.915 GHz are realized. As can be seen on figure, for Filter$\mathrm{C}$, one of the RZs are shifted to the right side of third band. So, it can be said that degenerate modes of the DMRs give the ability to control RZs location on frequency axis. The dimensions (in $\mathrm{mm}$ ) of loading and perturbation elements of each filter are given in Table 1 . Here, $\mathrm{p}_{1 \mathrm{x}}$ and $\mathrm{p}_{1 \mathrm{y}}$ are dimensions of perturbation elements and - (negative sign) means that the perturbation element has a cavity shape. $\mathrm{L}_{8}$, $\mathrm{W}_{3}$ and $\mathrm{L}_{2}, \mathrm{~W}_{2}$ are loading element dimensions. $\mathrm{W}_{4}$ is the height of the strip which shortened the coupled two adjacent DMRs.

On the other hand, Figure 4 shows the effect of loading and perturbation elements on the frequency responses. To examine the effect of the perturbation element on each resonator separately, one of them is kept constant and the variation of the other perturbation element is examined. So, it can be seen from Figure 4(a), the effect of each perturbation element has opposite effect on loop levels between the bands and in-band IL levels. Also, in Figure 4(b), the effect of loading elements on the frequency response is investigated in a similar way to the analysis of the effect of perturbation elements. In all cases, its observed that loading elements have similar effects as perturbation 
elements despite the bandwidth variation of second and third band. In addition, RZs named as $\mathrm{f}_{\mathrm{RZ \# 1}}, \mathrm{f}_{\mathrm{RZ \# 2}}$ and $\mathrm{f}_{\mathrm{RZ \# 3}}$ remain constant as perturbation and loading element dimensions are changing.

Figure 5 shows the simulated current distributions of RZs for Filter-A at $\mathrm{f}_{\mathrm{RZ} \# 1}=4.8 \mathrm{GHz}, \mathrm{f}_{\mathrm{RZ} \# 2}=5.7 \mathrm{GHz}, \mathrm{fA}_{\mathrm{RZ} \# 1}=10.9$ $\mathrm{GHz}, \mathrm{fA}_{\mathrm{RZ} \# 1}=11.95 \mathrm{GHz}$ and $\mathrm{f}_{\mathrm{RZ} \# 2}=14.55 \mathrm{GHz}$. As can be seen from the figure that the frequencies at 4.8, 5.7, 10.9, $11.95 \mathrm{GHz}$ have similar effect of current distributions, but at 14.55 GHz, the current distribution of the design has a maximum on a part of smaller DMR while on the other part is rejected. This rejection means that at this frequency $S_{11}$ has a value of negative infinite and correspondingly $S_{21}$ has maximum transition value. By using these definitions, it can be said that maximum transmission can be realized by the shortest way between the input and output ports at 14.65 $\mathrm{GHz}$ frequency

\section{Results and discussions}

The proposed triple wideband bandstop filter has had controllable RZs between the second and third band by using two direct coupled DMRs is depicted in Figure 2. Three triple wideband BSF are simulated via a full-wave EM simulator [9]. The simulated S-parameters is given in Figure 3 and summary of the simulated results of each filter are given in Table 2. One of the filters (Filter-A) which is fabricated on RT/Duroid substrate having thickness of 0.813 $\mathrm{mm}$ and a relative dielectric constant of 3.55. In Figure 6(a), the photograph of the fabricated filter and measured results are presented. The filter dimensions (in $\mathrm{mm}$ ) are $\mathrm{a}=9.2, \mathrm{~b}=$ 5.6, $\mathrm{L}_{1}=2.1, \mathrm{~L}_{3}=1.9, \mathrm{~L}_{4}=2.7, \mathrm{~L}_{5}=1.8, \mathrm{~L}_{6}=4.6, \mathrm{~L}_{7}=4.0, \mathrm{~L}_{9}=$ 6.9 and $\mathrm{W}_{1}=0.3$. Also, perturbation and loading element dimensions are given in Table 1. Figure 6(b) shows the comparison of the measured and simulated results for FilterA. Measurements were realized by a Vector Network Analyzer HP8720C. According to the results, fo, RL and FBW values are, for first band is $2.545 \mathrm{GHz}, 0.47 \mathrm{~dB}$ and $62.4 \%$, for second band, $8.04 \mathrm{GHz}, 0.034$ and $52.7 \%$ and for third band, $13.407 \mathrm{GHz}$, nearly $3 \mathrm{~dB}$ and $16.3 \mathrm{~dB}$, respectively. Since the sensitivity of the measuring instrument deteriorates at high frequencies, difficulties were experienced in the measurement of the third band.

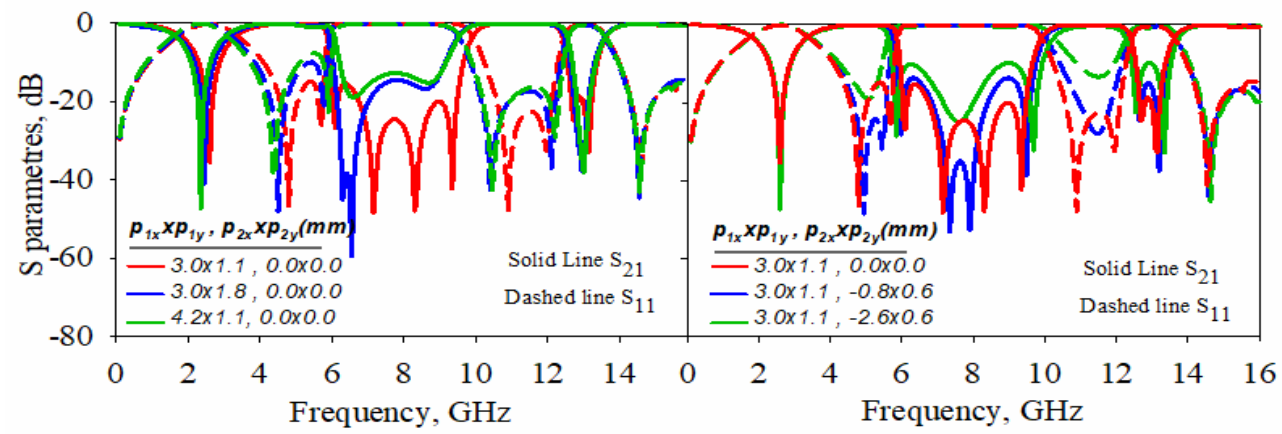

(a)

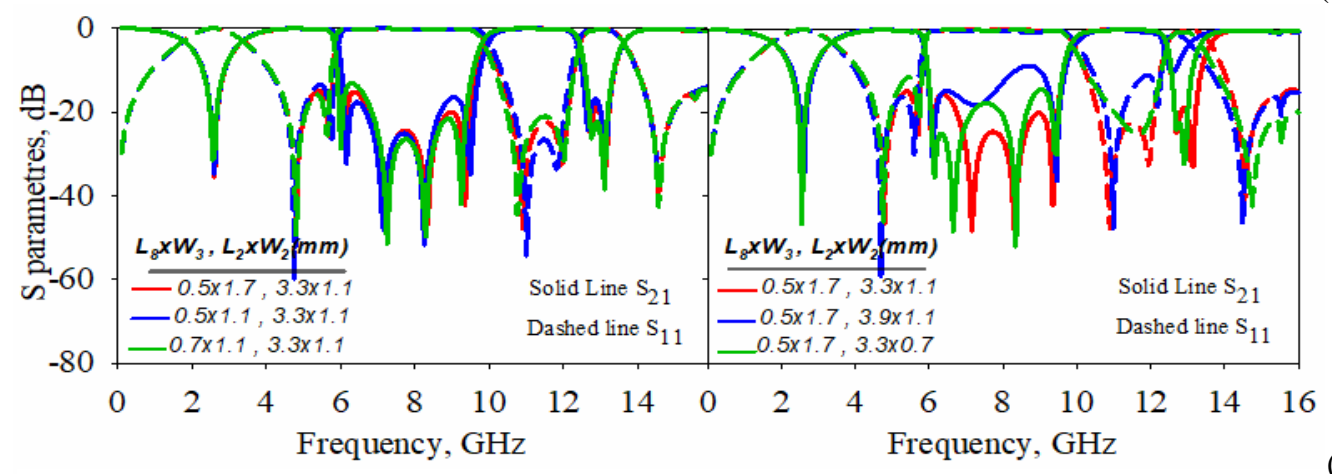

(b)

Figure 4. S-parameters variation of Filter-A for(a) perturbation elements (b) loading elements

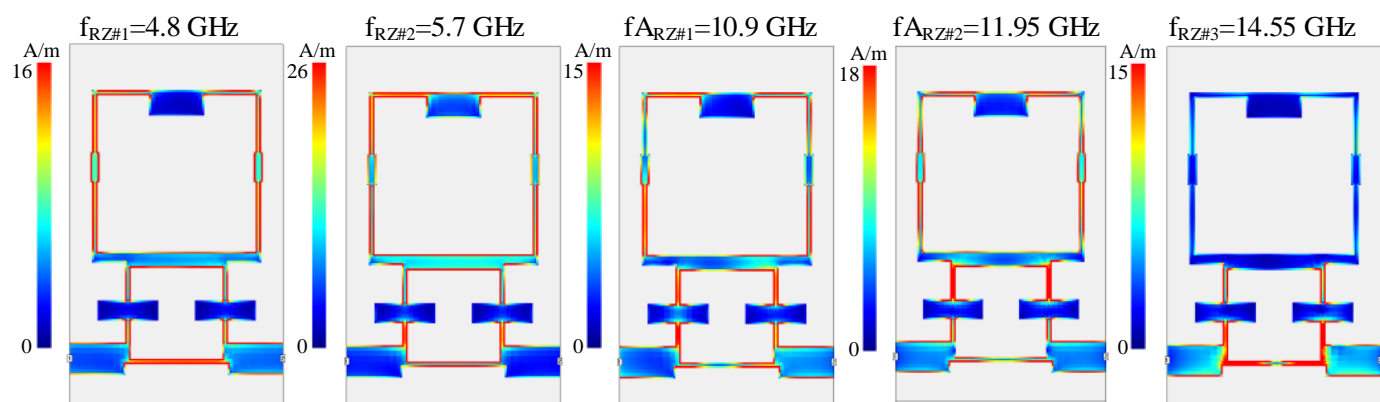

Figure 5. Simulated current distributions for Filter-A at $4.8 \mathrm{GHz}, 5.7 \mathrm{GHz}, 10.9 \mathrm{GHz}, 11.95 \mathrm{GHz}$ and $14.55 \mathrm{GHz}$ 


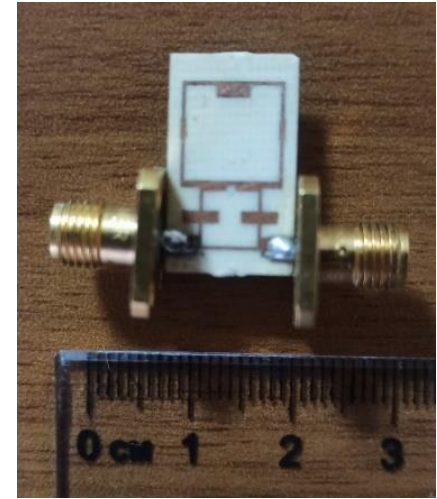

(a)

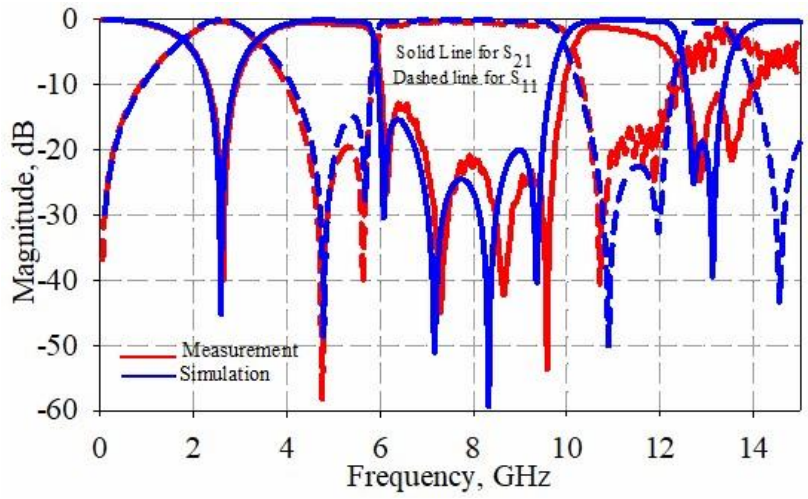

(b)

Figure 6. (a) Fabricated filter photograph for Filter-A (b) Comparison of the measured and simulated results for Filter-A

Table 1. The dimensions of loading and perturbation elements for Filter-A, Filter-B and Filter-C

\begin{tabular}{lccccc}
\hline Filter Name & $\mathrm{p}_{1 \mathrm{x}}, \mathrm{p}_{1 \mathrm{y}}$ & $\mathrm{p}_{2 \mathrm{x}}, \mathrm{p}_{2 \mathrm{y}}$ & $\mathrm{L}_{8}, \mathrm{~W}_{3}$ & $\mathrm{~L}_{2}, \mathrm{~W}_{2}$ & $\mathrm{~W}_{4}$ \\
\hline Filter-A & $3.0 \times 1.1$ & - & $0.5 \times 1.7$ & $3.3 \times 1.1$ & 0.3 \\
Filter-B & $3.0 \times 1.1$ & $-0.8 \times 0.6$ & $0.5 \times 1.7$ & $3.3 \times 1.1$ & 0.3 \\
Filter-C & $4.2 \times 1.8$ & $2.6 \times 1.0$ & $0.7 \times 1.1$ & $3.9 \times 1.1$ & - \\
\hline
\end{tabular}

Table 2. Simulated results for triple wideband BSFs

\begin{tabular}{lccccccccc}
\hline \multirow{2}{*}{$\begin{array}{l}\text { Filter } \\
\text { Name }\end{array}$} & \multicolumn{3}{c}{ First Band } & \multicolumn{3}{c}{ Second Band } & \multicolumn{3}{c}{ Third Band } \\
\cline { 2 - 10 } & RL $(\mathrm{dB})$ & $\mathrm{f}_{0}(\mathrm{GHz})$ & FBW $(\%)$ & $\mathrm{RL}(\mathrm{dB})$ & $\mathrm{f}_{0}(\mathrm{GHz})$ & $\mathrm{FBW}(\%)$ & $\mathrm{RL}(\mathrm{dB})$ & $\mathrm{f}_{0}(\mathrm{GHz})$ & FBW $(\%)$ \\
\hline Filter-A & -0.045 & 2.57 & 62 & -0.13 & 7.89 & 51 & -0.43 & 13.025 & 9 \\
Filter-B & -0.038 & 2.59 & 62 & -0.12 & 7.89 & 54 & -0.46 & 13.01 & 9 \\
Filter-C & 0.047 & 2.35 & 60 & -0.14 & 7.48 & 45 & -0.58 & 12.225 & 8.2 \\
\hline
\end{tabular}

\section{Conclusions}

In this study, a novel compact triple wideband BSF design is proposed by using adjacent square loop DMRs having unequal edge sizes. Direct coupling mechanism and perturbation elements are used to realize multiband filtering responses as a result of excitation the degenerate modes of the DMRs. In addition, both loading and perturbation element usage leaded to the ability to control the RZs between the second and third band. Also, IL levels inside stopband can also be controlled by using these elements. Designed filters have high performance and small size despite having multiple wideband filtering characteristic. Even odd mode analyzes of a single square loop DMR having asymmetrical direct coupling with loading elements are also extracted to clarify the filter topology. Three filters are designed by using a full-wave EM simulator and one of them were manufactured and measured. Simulated and measurement results show a good agreement.

\section{Conflict of Interest}

The author has no conflicts of interest to declare

\section{Similarity (iThenticate): \%14}

\section{References}

[1] I. Wolff, Microstrip bandpass filter using degenerate modes of a microstrip ring resonator. Electronics
Letters, 8 (12), 302-303, 1972. https://doi.org/10.1049 /el:19720223.

[2] M-L. Her, Q-M. Kin, K-Y. Lin, Y-D. Wu and Y-L. Wang, Dual-Mode and Three-Transmission-Zeros bandstop filters with closed-loop ring resonators. Microwave and Optical Technology Letters, 44 (2), 114-118, (2005). http://dx.doi.org/10.1002/mop.20562

[3] B. Shrestha and N-Y. Kim, Adjustable wideband bandstop filter with inductive coupling for ultrawideband applications. Microwave and Optical Technology Letters, 57 (8), 1901-1905, (2015). http:// dx.doi.org/10.1002/mop.29226

[4] L-H. Hsieh and K. Chang, Compact, low insertion-loss, sharp-rejection, and wide-band microstrip bandpass filters. IEEE Transactions on Microwave Theory and Techniques, $51 \quad$ (4), 1241-1246, (2003). https://doi.org/10.1109/TMTT.2003.809643

[5] L. Bousbia, M. Mabrouk and A. Ghazel, Study and modeling of $\mathrm{T}$ and $\mathrm{L}$ shaped resonators for UWB band pass filter. EuroCon, pp. 1857-1861, Zagreb, Croatia, 2013. https://doi.org/10.1109/EUROCON.2013. 6625230

[6] E. Gunturkun Sahin, A. K. Gorur, C. Karpuz and A. Gorur, A novel compact wideband bandstop filter design using a dual-mode square loop resonator. AsiaPacific Microwave Conference, pp. -, New Delhi, India, (2016). https://doi.org/10.1109/APMC.2016. 7931430 
[7] J.S. Hong and M.J. Langester, Microstrip Filters for RF/Microwave Applications, Wiley, Newyork, 2001.

[8] A. Gorur, Description of coupling between degenerate modes of a dual-mode microstrip loop resonator using a novel perturbation arrangement and its dual-mode bandpass filter applications. IEEE Transactions on
Microwave Theory and Techniques 52 (2), 671- 677, (2004). http://dx.doi.org/10.1109/TMTT.2003.822033

[9] Sonnet User's Manual, Version 14, Sonnet Software, North Syracuse, NY, 2011. 